Brief Report

\title{
Detection of fecal SARS-CoV-2 RNA in a prospective cohort of children with multisystem inflammatory syndrome (MIS-C)
}

\author{
Emilia Parodi 1,2*, Andrea Carpino ${ }^{3}$, Elena Franchitti ${ }^{2}$, Giulia Pruccoli ${ }^{1,2}$, Marco Denina ${ }^{1,2}$, Federica Pagliero ${ }^{2}$, \\ Ugo Ramenghi ${ }^{2}$ and Deborah Traversi ${ }^{2}$ \\ 1 Regina Margherita Children' s Hospital, A.O.U. Città della Salute e della Scienza, Torino, Italy
2 Department of Public Health and Pediatrics, University of Torino, Torino, Italy
3 Postgraduate School of Pediatrics, University of Torino, Torino, Italy
* Correspondence: emilia.parodi@unito.it (mail); Tel + 390113135798 (office); I-1026 Torino, Italy
}

\begin{abstract}
Multisystem inflammatory syndrome related to SARS-CoV-2 infection (MIS-C) is a rare severe illness affecting paediatric patients. No data are available in literature about the presence of SARS-CoV-2 RNA in faces in patients with MIS-C. The SARS-CoV-2 positivity was evaluated in fecal samples obtained in a prospective cohort of paediatric patients admitted to our tertiary Hospital and diagnosed with MIS-C or COVID-19 between April 15, 2020, and February 29, 2021. The real-time RT-PCR was performed using a validated kit. The assay measures 3 target genes: SARS-CoV-2 gene E, gene N, gene ORF1ab. Overall, 16/63 (25\%) fecal samples revealed the presence of SARS -CoV-2 RNA. No differences were detected about time from presumptive viral exposure and the time of stool collection (14 vs 8 days, $\mathrm{p}>0,05)$ as well as about the presence of gastrointestinal symptoms ( $\mathrm{p}>0.05)$ between patients with positive $(+)$ stools for SARS-CoV-2 RNA and patients tested negative (-). Among children with MIS-C, stools were collected 27.5 days as median (95\% CI 14-34) after presumed contact and the positivity rate was $12.5 \%$ (4/32). According to our data, we could suggest contact precautions with all patients with MIS-C. Further sample collection is ongoing to verify our preliminary data.
\end{abstract}

Keywords: SARS-CoV-2; stools; COVID-19; MIS-C; children

\section{Introduction}

Multisystem inflammatory syndrome related to SARS-CoV-2 infection (MIS-C) is a rare but severe illness affecting paediatric patients firstly described in April 2020, approximately one month after the first COVID-19 outbreak [1,2]. MIS-C usually develops after the infection rather than during the acute stage of the disease, suggesting a dysregulated immune response (i.e. continuous activation of adaptive immune responses driven by persisting antigen presentation) as the primary pathogenic mechanism [3]. Only one-third of reported cases, indeed, present a positive RT-PCR for SARS-CoV-2 on nasal swab; on the contrary, in most cases the serology results positive, suggesting a past infection $[4,5]$.

MIS-C clinical presentation, characterized by multi-organ involvement, commonly involves gastrointestinal signs and symptoms [6-8]. To the best of our knowledge, no data are present in literature regarding the detection of SARS-CoV-2 RNA in fecal samples of patients with MIS-C, even if biospecimen collection methods for children were recently proposed [9].

The present prospective study aimed to detect SARS-CoV-2 RNA in fecal samples of patients who met CDC case definition criteria for MIS-C, admitted to our tertiary care paediatric hospital in the North-West of Italy between April 2020 and February 2021. 


\section{Materials and Methods}

All patients admitted to Regina Margherita Children's Hospital (Turin, Italy) and diagnosed with MIS-C between April 15, 2020, and February 29, 2021, were prospectively enrolled in the study. Children admitted in the same period for COVID-19 or followed up in outpatients' service after hospitalization for COVID-19 were included as control group. Written informed consent was obtained from the parents of patients. Approval was obtained from Institutional Ethical Committee (Città della Salute e della Scienza di Torino, protocol number 00564/2020).

Fecal samples obtained after admission were stored at $-80^{\circ} \mathrm{C}$, immediately after collection, until the extraction and analysis were performed in the lab (Hygiene Section, Public Health and Pediatric Department, University of Turin). Extraction of total RNA from fecal samples was performed with a commercialized kit (Power Microbiome RNA kit, QIAGEN). The extracted RNA was quantified using a NanoQuant Plate (TECAN Trading AG, Switzerland), which allows quantification using a spectrophotometer read at $260 \mathrm{~nm}$. The spectrophotometer used was the TECAN Infinite $200 \mathrm{PRO}$, and the software was i-Control (version 1.11.10). The extracted RNA concentration was meanly $17.6 \pm$ $25.6 \mu \mathrm{g} / \mathrm{mg}$ stool. Samples were stored at $-80^{\circ} \mathrm{C}$ until molecular analysis was performed.

The real-time RT-PCR was performed using the Novel Coronavirus (2019-nCoV) Real-Time Multiplex RT-PCR kit from LifeRiver Ltd., and CFX Instruments (Bio-Rad, Hercules, CA, USA) following the suggested thermal protocol included in the kit instructions and according to literature data [10]. The assay measures simultaneously 3 target genes: SARS-CoV-2 gene $\mathrm{E}$, gene $\mathrm{N}$, gene ORF1ab according to international validated testing protocols $[10,11]$.

For each patient enrolled in the study, demographic data, clinical presentation and time from SARS-CoV-2 infection to fecal sample collection were registered (Table 1A). The time from the presumptive contact with the virus was defined as follow:

a) when available, we considered the date of the first positive SARS-CoV-2 nasopharyngeal swab with the addiction of 4 days as typical incubation period [12];

b) for patients with MIS-C without previous positive swab and ascertained intrafamilial exposure to SARS-CoV-2, we considered the date of the first positive SARS-CoV-2 swab of familial contacts;

c) for patients with MIS-C without positive swab and untested intrafamilial exposure, we considered 15 days as the minimum time to produce specific antibodies from exposure.

The statistical analysis was performed using IBM SPSS statistics package 27.0. A descriptive analysis of the variables was conducted. The data were reported as absolute numbers and percentages for categorical variables while as medians and confidence intervals - 95\% higher and 5\% lower - for continuous variables. Moreover, the subjects were divided into two groups based on the diagnosis: COVID-19 or MIS-C. Differences between COVID-19 and MIS-C children were assessed using $\chi^{2}$ test with Fisher's correction for categorical variables and Median test for independent samples for continuous variables. The Spearman rank-order correlation coefficient was also determined to assess the relationships between variables. A p-value $\mathrm{p}<0.05$ was considered significant for all analyses.

\section{Results}

\subsection{Patients' characteristics}

Overall, 63 patients (28 females and 35 males, aged 1 months to 15 years) were prospectively enrolled in the study (Table 1A).

Thirty-two children fulfilled CDC case definition criteria for MIS-C [13,14]. Among 31 patients with COVID-19, 24 were enrolled during the acute stage of the disease, and 7 
at the follow- up in outpatients' clinic. Clinical and demographic characteristics of patients are reported in Table 1A.

Data regarding IgG against SARS-CoV-2 were available for 28/32 patients with MIS-C, as 4 children were enrolled before the development of validated methods; 27/28 $(96 \%)$ children had a positive serology, confirming past infection. All patients with COVID-19 displayed at least one positive Real-Time Polymerase Chain Reaction (RT-PCR) nasal swab for SARS-CoV-2.

\section{- Gastrointestinal symptoms and fecal SARS-CoV-2 data}

Gastrointestinal symptoms (i.e. at least one among abdominal pain, nausea, vomiting or diarrhoea) were reported in 9/31 (29\%) patients with COVID-19 and 26/32 (81\%) children with MIS-C, with a statistically significant difference between the two groups ( $\mathrm{p}$ $=0.000$ ).

Overall, 16/63 (25\%) fecal samples revealed the presence of SARS -CoV-2 RNA.

No differences were detected about time from presumptive viral exposure and the time of stool collection (14 vs 8 days, $p>0,05)$ as well as about the presence of gastrointestinal symptoms ( $p>0.05)$ between patients with positive $(+)$ stools for SARS-CoV-2 RNA and patients tested negative (-). In particular, the positivity rate of stools was comparable in patients with or without gastrointestinal clinical involvement, 37.5\% (6/35) vs $35 \%(10 / 28), \mathrm{p}>0.05$.

In patients with COVID-19, fecal samples were collected 8 days as median $(95 \%$ CI 7-13) after the presumed viral exposure and were positive in 12/31 (39\%); among children with MIS-C, stools were collected 27.5 days as median (95\% CI 14-34) after presumed contact and the positivity rate was $12.5 \%(4 / 31)$. (Table 1B). Positive stools of patients with MIS-C were collected at 27, 36, 43 and 72 days from presumptive primary infection (Figure 1); in the latter, concomitant serology for SARS-CoV-2 resulted negative, but the exposure to a confirmed COVID-19 case was ascertained.

\subsection{Figures and Tables}

Figure 1. Distribution of the samples concerning the esteemed time from the SARS-CoV-2 contact causing the following COVID-19 or MIS-C and stool positivity (red).

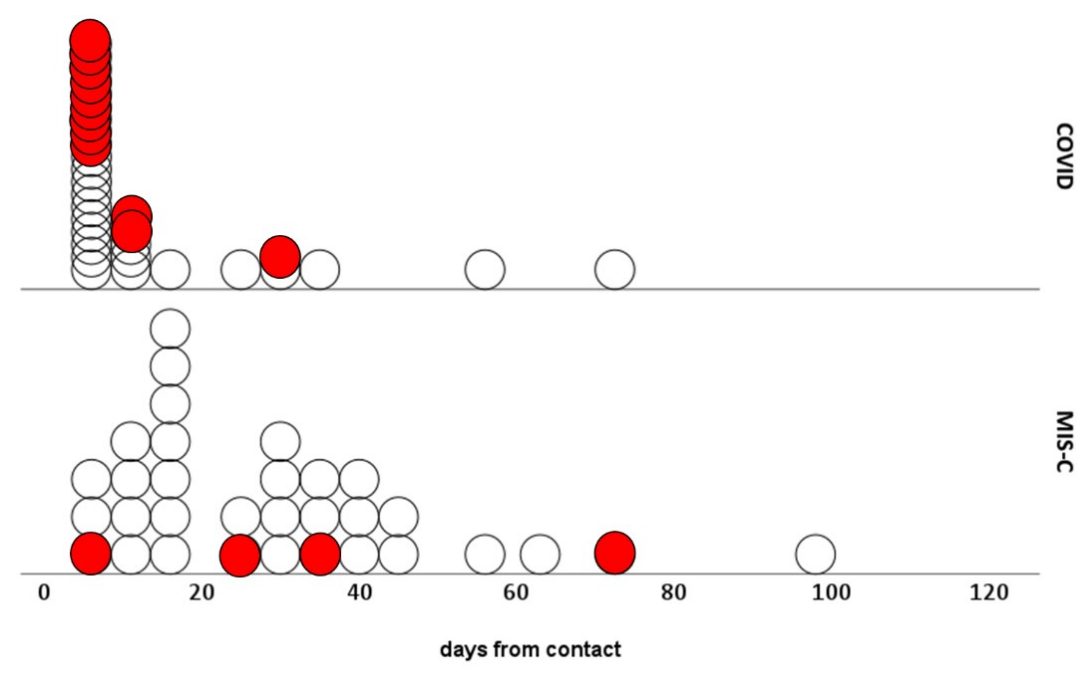

Table 1. Demographic characteristics (A), gastrointestinal symptoms and fecal SARS-CoV-2 collected data (B) of the two patient cohorts. Continuous variables are expressed as median and con- 
fidence interval (IC 5-95\%); the categorical variables are expressed as absolute numbers and percentages. Bolded $\mathrm{p}$ values are statistically significant

\begin{tabular}{|c|c|c|c|c|c|}
\hline & & & $\begin{array}{l}\text { COVID-19 } \\
(n=31)\end{array}$ & $\begin{array}{l}\text { MIS-C } \\
(n=32)\end{array}$ & $\begin{array}{c}\mathrm{p} \\
\text { value }\end{array}$ \\
\hline \multirow{12}{*}{ A } & \multirow{2}{*}{ Gender } & Female & $\begin{array}{c}14 \\
(45.2)\end{array}$ & $\begin{array}{c}14 \\
(43.8)\end{array}$ & \multirow{2}{*}{$\mathrm{p}>0.05$} \\
\hline & & Male & $\begin{array}{c}17 \\
(54.8)\end{array}$ & $\begin{array}{c}18 \\
(56.2)\end{array}$ & \\
\hline & \multirow{4}{*}{ Ethnicity } & Africans & $\begin{array}{c}4 \\
(12.9)\end{array}$ & $\begin{array}{c}4 \\
(12.5)\end{array}$ & \multirow{4}{*}{$p>0.05$} \\
\hline & & Caucasian & $\begin{array}{c}26 \\
(83.9)\end{array}$ & $\begin{array}{c}26 \\
(81.25)\end{array}$ & \\
\hline & & Chinese & $\begin{array}{c}1 \\
(3.2)\end{array}$ & $\begin{array}{r}0 \\
(0)\end{array}$ & \\
\hline & & Hispanic & $\begin{array}{c}0 \\
(0)\end{array}$ & $\begin{array}{c}2 \\
(6.25)\end{array}$ & \\
\hline & Age & years & $\begin{array}{c}5 \\
(2-9)\end{array}$ & $\begin{array}{c}8 \\
(7-11)\end{array}$ & $p>0.05$ \\
\hline & \multirow{2}{*}{ Antibodies against Sars-CoV-2 } & $\operatorname{IgG} \quad(+)$ & \multirow{2}{*}{ NA } & $\begin{array}{l}27^{1} \\
(96)\end{array}$ & \\
\hline & & $\operatorname{IgG} \quad(-)$ & & $\begin{array}{c}1 \\
(4)\end{array}$ & \\
\hline & \multirow{2}{*}{ Nasopharyngeal swab } & $\operatorname{Pos}(+)$ & $\begin{array}{c}31 \\
(100)\end{array}$ & $\begin{array}{c}10 \\
(31.2)\end{array}$ & \multirow{2}{*}{$\mathrm{p}=0.000$} \\
\hline & & $\operatorname{Neg}(-)$ & $\begin{array}{c}0 \\
(0)\end{array}$ & $\begin{array}{c}22 \\
(68.7)\end{array}$ & \\
\hline & $\begin{array}{l}\text { Esteemed time from the } \\
\text { Sars-CoV-2 contact }\end{array}$ & days & $\begin{array}{c}8 \\
(7-13)\end{array}$ & $\begin{array}{c}27.5 \\
(14-34)\end{array}$ & $\mathrm{p}=0.003$ \\
\hline \multirow{5}{*}{ B } & Extracted RNA from stool & $\mu g / \mu \mathrm{L}$ & $\begin{array}{c}69.6 \\
(33.7-128.3)\end{array}$ & $\begin{array}{c}22.8 \\
(11.6-50.3)\end{array}$ & $\mathrm{p}>0.05$ \\
\hline & \multirow{2}{*}{ Gastrointestinal symptoms } & No & $\begin{array}{l}22 \\
(71)\end{array}$ & $\begin{array}{c}6 \\
(18.75)\end{array}$ & \multirow{2}{*}{$\mathrm{p}=\mathbf{0 . 0 0 0}$} \\
\hline & & Yes & $\begin{array}{c}9 \\
(29)\end{array}$ & $\begin{array}{c}26 \\
(81.25)\end{array}$ & \\
\hline & \multirow{2}{*}{ Sars-CoV-2 RNA in stool } & Neg (-) & $19(61.3)$ & $28(87.5)$ & \multirow{2}{*}{$\begin{array}{c}\mathrm{p}=0.017 \\
2\end{array}$} \\
\hline & & $\operatorname{Pos}(+)$ & $12(38.7)$ & $4(12.5)$ & \\
\hline
\end{tabular}

1 data available only for 28 patients with MIS-C

2 the few data included in any groups can affect the test significantly 


\section{Discussion}

Multisystem inflammatory syndrome related to SARS-CoV-2 infection (MIS-C) is a severe emerging illness affecting paediatric patients [1,2].

The SARS-CoV-2 attachment site, i.e. the angiotensin-converting enzyme 2 (ACE-2 receptor), is widely expressed also in the gut [15-18]. Previous studies have already demonstrated the presence of SARS-CoV-2 RNA in faeces of almost one third of patients with COVID-19 [19-24]. The contagiousness of the virus within the gut and the possible fecal-oral route of transmission, however, remain unproven [19,25-29].

Multiple studies have reported gastrointestinal symptoms in children with COVID-19, with diarrhoea, nausea, vomiting, anorexia and abdominal pain being described as the main symptoms $[6,28]$. Children, compared to adults, have a higher ACE-2 expression in the gut [15] and present a higher ACE expression inside the intestine than in the respiratory tract [24]; these data may explain both the higher proportion of gastrointestinal symptoms and the higher percentage of positive faeces in the paediatric than in the adult form of COVID-19 [15].

MIS-C clinical presentation, characterized by multi-organ involvement, commonly includes gastrointestinal signs and symptoms. According to literature data [6-8], in our cohort diarrhoea, nausea, vomiting or abdominal pain were more frequent in patients with MIS-C compared to children with COVID-19 (respectively more than $75 \%$ in the first group vs less than $30 \%$ in the second one); this difference resulted statistically significant $(\mathrm{p}<0.000)$.

To the best of our knowledge, data regarding the presence of the virus in the gut of patients with MIS-C are lacking. In our prospective cohort of pedaitric patients with MIS-C, more than $10 \%$ of patients tested positive (+) for SARS-CoV-2 RNA in faeces. The rate of patients with acute COVID-19 and fecal SARS-CoV-2 positivity (39\%) was consistent with previously reported data [24], confirming the reliability of our methods.

Despite the limits deriving from the small number of patients with MIS-C tested positive (+) for SARS-CoV-2 fecal RNA, some preliminary conclusions could be drawn. First, it should be noted that there is no difference in the occurrence rate of gastrointestinal symptoms between patients with MIS-C with a positive (+) or a negative (-) result for SARS-CoV-2-RNA in the stools. Whether the virus titres in fecal fomites are of sufficient concentration and infectivity for subsequent transmission remains unknown, even in patients with acute COVID-19 [19,25-29]. Nevertheless, due to the impossibility of clinically differentiating in our cohort children with positive $(+)$ stools $(>10 \%)$ from the others with negative (-) stools, we suggest contact precautions during hospitalization to be taken in all patients with MIS-C.

In addition, the wide range of days observed between presumed primary viral infection and detection of viral RNA in faeces (72, 43, 36 and 27 days) does not permit to determine precisely how long these precautions should be applied in children with MIS-C.

Further sample collection is ongoing to verify our preliminary data on a larger cohort.

To further complete the study, gut microbiota analysis on DNA extracted from fecal samples of our patients with MIS-C will be performed in the next months. In adults, microbiota modulation linked to SARS-CoV-2-host interaction has been proven to promote inflammation (through reduction of short-chain fatty acid producers and increase of pathogenic microorganisms) [30,31]. The quite long pre-symptomatic phase in MIS-C suggests an additional trigger that likely occurs 2-4 weeks after the initial infection; in this context, microbiota might represent a crucial key to explain the mechanism of disease onset. As a consequence, complete microbiota analysis could be an innovative approach to better understand MIS-C pathogenesis and identify potential early biomarkers of susceptibility to this emerging paediatric disease. 
Author Contributions: EP and DT and UR gave substantial contribution to conception and design, drafted the article, reviewed and critically revised the manuscript; DT and EF made stool sample processing and extraction and bio-molecular analysis; DT made statistical analysis and bioinformatic; AC, EF, GP, FP and MD contributed to conception and design, collected data, and revised the manuscript; all authors approved the final version of the manuscript and agree to be accountable for all aspects of the work.

Funding: This research received no external funding.

Institutional Review Board Statement: The study was conducted according to the guidelines of the Declaration of Helsinki, and approved by the Ethics Committee of Città della Salute e della Scienza di Torino, protocol number 00564/2020.

Informed Consent Statement: Written informed consent has been obtained from the parents of the patients to publish this paper.

Acknowledgments: the Authors thank the University of Torino and all the physicians and nurses personnel involved in the patients' care. The Authors make a special acknowledgement to the children and to their families.

Conflicts of Interest: The authors declare no conflict of interest.

\section{References}

[1] Carbajal R, Lorrot M, Levy Y, Grimprel E, Lecarpentier T, Heritier S, et al. Multisystem inflammatory syndrome in children rose and fell with the first wave of the COVID-19 pandemic in France. Acta Paediatrica, International Journal of Pediatrics 2021;110:922-32. doi:10.1111/apa.15667.

[2] Blumenthal JA, Burns JP. Epidemiology of Multisystem Inflammatory Syndrome in Children: A Step Closer to Understanding Who, Where, and When. JAMA Pediatrics 2021. doi:10.1001/jamapediatrics.2021.0638.

[3] Gruber CN, Patel RS, Trachtman R, Lepow L, Amanat F, Krammer F, et al. Mapping Systemic Inflammation and Antibody Responses in Multisystem Inflammatory Syndrome in Children (MIS-C). Cell 2020;183:982-995.e14. doi:10.1016/j.cell.2020.09.034.

[4] Henderson LA, Canna SW, Friedman KG, Gorelik M, Lapidus SK, Bassiri H, et al. American College of Rheumatology Clinical Guidance for Multisystem Inflammatory Syndrome in Children Associated With SARS-CoV-2 and Hyperinflammation in Paediatric COVID-19: Version 1. Arthritis \& Rheumatology 2020. doi:10.1002/art.41454.

[5] Rostad CA, Chahroudi A, Mantus G, Lapp SA, Teherani M, Macoy L, et al. Quantitative SARS-CoV-2 Serology in Children With Multisystem Inflammatory Syndrome (MIS-C). Pediatrics 2020;146.

[6] Lee IC, Huo TI, Huang YH. Gastrointestinal and liver manifestations in patients with COVID-19. Journal of the Chinese Medical Association 2020;83:521-3. doi:10.1097/JCMA.0000000000000319.

[7] Aronoff SC, Hall A, Del Vecchio MT. The Natural History of Severe Acute Respiratory Syndrome Coronavirus 2-Related Multisystem Inflammatory Syndrome in Children: A Systematic Review. Journal of the Paediatric Infectious Diseases Society 2020;9:746-51. doi:10.1093/jpids/piaa112.

[8] Radia T, Williams N, Agrawal P, Harman K, Weale J, Cook J, et al. Multi-system inflammatory syndrome in children \& adolescents (MIS-C): A systematic review of clinical features and presentation. Pediatric Respiratory Reviews 2020. doi:10.1016/j.prrv.2020.08.001.

[9] Lima R, Gootkind EF, De La Flor D, Yockey LJ, Bordt EA, D’Avino P, et al. Establishment of a paediatric COVID-19 biorepository: Unique considerations and opportunities for studying the impact of the COVID-19 pandemic on children. BMC Medical Research Methodology 2020;20:1-11. doi:10.1186/s12874-020-01110-y.

[10] Mesoraca A, Margiotti K, Viola A, Cima A, Sparacino D, Giorlandino C. Evaluation of SARS-CoV-2 viral RNA in fecal 
samples. Virology Journal 2020;17:1-3. doi:10.1186/s12985-020-01359-1.

[11] Corman VM, Landt O, Kaiser M, Molenkamp R, Meijer A, Chu DK, et al. Detection of 2019 -nCoV by RT-PCR. Euro Surveill 2020;25:1-8.

[12] Zimmermann P, Curtis N. Coronavirus infections in children including COVID-19: An overview of the epidemiology, clinical features, diagnosis, treatment and prevention options in children. Pediatric Infectious Disease Journal 2020;39:355-68. doi:10.1097/INF.0000000000002660.

[13] Centers for Disease Control and Prevention. Information for Healthcare Providers about Multisystem Inflammatory Syndrome in Children (MIS-C) n.d.

[14] Jiang L, Tang K, Levin M, Irfan O, Morris SK, Wilson K, et al. COVID-19 and multisystem inflammatory syndrome in children and adolescents. The Lancet Infectious Diseases 2020;3099. doi:10.1016/S1473-3099(20)30651-4.

[15] Canani RB, Comegna M, Paparo L, Cernera G, Bruno C, Strisciuglio C, et al. Comparative Evaluation of Nasal and Small Intestine Expression of ACE2, TMPRSS2 and ACE1 and in Children and in Adults. SSRN Electronic Journal 2020. doi:10.2139/ssrn.3714641.

[16] Zhang H, Li HB, Lyu JR, Lei XM, Li W, Wu G, et al. Specific ACE2 expression in small intestinal enterocytes may cause gastrointestinal symptoms and injury after 2019-nCoV infection. International Journal of Infectious Diseases 2020;96:19-24. doi:10.1016/j.ijid.2020.04.027.

[17] da Luz BB, de Oliveira NMT, França dos Santos IW, Paza LZ, Braga LLV de M, Platner F da S, et al. An overview of the gut side of the SARS-CoV-2 infection. Intestinal Research 2020:1-7. doi:10.5217/ir.2020.00087.

[18] Ziegler CGK, Allon SJ, Nyquist SK, Mbano IM, Miao VN, Tzouanas CN, et al. SARS-CoV-2 Receptor ACE2 Is an Interferon-Stimulated Gene in Human Airway Epithelial Cells and Is Detected in Specific Cell Subsets across Tissues. Cell 2020;181:1016-1035.e19. doi:10.1016/j.cell.2020.04.035.

[19] Ding S, Liang TJ. Is SARS-CoV-2 Also an Enteric Pathogen With Potential Fecal-Oral Transmission? A COVID-19 Virological and Clinical Review. Gastroenterology 2020;159:53-61. doi:10.1053/j.gastro.2020.04.052.

[20] Wong MC, Huang J, Lai C, Ng R, Chan FKL, Chan PKS. Detection of SARS-CoV-2 RNA in fecal specimens of patients with confirmed COVID-19: A meta-analysis. Journal of Infection 2020;81:e31-8. doi:10.1016/j.jinf.2020.06.012.

[21] Galanopoulos M, Gkeros F, Doukatas A, Karianakis G, Pontas C, Tsoukalas N, et al. COVID-19 pandemic: Pathophysiology and manifestations from the gastrointestinal tract. World Journal of Gastroenterology 2020;26:4579-88. doi:10.3748/WJG.V26.I31.4579.

[22] Xiong XL, Wong KKY, Chi SQ, Zhou AF, Tang JQ, Zhou LS, et al. Comparative study of the clinical characteristics and epidemiological trend of 244 COVID-19 infected children with or without GI symptoms. Gut 2021;70:436-8. doi:10.1136/gutjnl-2020-321486.

[23] Xiao F, Tang M, Zheng X, Liu Y, Li X, Shan H. Evidence for Gastrointestinal Infection of SARS-CoV-2. Gastroenterology 2020;158:1831-1833.e3. doi:10.1053/j.gastro.2020.02.055.

[24] Zhang JC, Wang S Bin, Xue YD. Fecal specimen diagnosis 2019 novel coronavirus-infected pneumonia. Journal of Medical Virology 2020;92:680-2. doi:10.1002/jmv.25742.

[25] Mirjalali H, Nazemalhosseini-Mojarad E, Yadegar A, Mohebbi SR, Baghaei K, Shahrokh S, et al. The Necessity of Stool Examination in Asymptomatic Carriers as a Strategic Measure to Control Further Spread of SARS-CoV-2. Frontiers in Public Health 2020;8. doi:10.3389/fpubh.2020.553589.

[26] Godoy MG, Kibenge MJT, Kibenge FSB. SARS-CoV-2 transmission via aquatic food animal species or their products: A review. Aquaculture 2021;536:736460. doi:10.1016/j.aquaculture.2021.736460.

[27] $\mathrm{Xu} \mathrm{Y,} \mathrm{Liu} \mathrm{P,} \mathrm{Gu} \mathrm{J.} \mathrm{Gastrointestinal} \mathrm{and} \mathrm{liver} \mathrm{involvement} \mathrm{in} \mathrm{patients} \mathrm{with} \mathrm{COVID-19.} \mathrm{The} \mathrm{Lancet} \mathrm{Gastroenterology} \mathrm{and}$ Hepatology 2020;5:798-9. doi:10.1016/S2468-1253(20)30205-3. 
[28] Scaldaferri F, Ianiro G, Privitera G, Lopetuso LR, Vetrone LM, Petito V, et al. The thrilling journey of sars-cov-2 into the intestine: From pathogenesis to future clinical implications. Inflammatory Bowel Diseases 2020;26:1306-14. doi:10.1093/ibd/izaa181.

[29] Heller L, Mota CR, Greco DB. COVID-19 fecal-oral transmission: Are we asking the right questions? Science of the Total Environment 2020;729. doi:10.1016/j.scitotenv.2020.138919.

[30] Yeoh YK, Zuo T, Lui GCY, Zhang F, Liu Q, Li AYL, et al. Gut microbiota composition reflects disease severity and dysfunctional immune responses in patients with COVID-19. Gut 2021;70:698-706. doi:10.1136/gutjnl-2020-323020.

[31] Zuo T, Zhang F, Lui GCY, Yeoh YK, Li AYL, Zhan H, et al. Alterations in Gut Microbiota of Patients With COVID-19 During Time of Hospitalization. Gastroenterology 2020;159:944-955.e8. doi:10.1053/j.gastro.2020.05.048. 